\title{
Aplicações clínicas do enceramento diagnóstico na reabilitação oral - uma revisão de literatura
}

\author{
Clinical applications of diagnostic wax-up in \\ oral rehabilitation - a literature review
}

\author{
LIS MeIRELLes \\ Mestranda do Departamento de Prótese Dentária e Periodontia Faculdade \\ de Odontologia de Piracicaba, UNICAMP Universidade Estadual de Campinas \\ Paula Furlan Bavia \\ Mestranda do Departamento de Prótese Dentária e Periodontia \\ Faculdade de Odontologia de Piracicaba, \\ UNICAMP Universidade Estadual de Campinas. \\ LaRISSA Soares ReIs VILANova \\ Doutoranda do Departamento de Prótese Dentária e Periodontia Faculdade \\ de Odontologia de Piracicaba, UNICAMP Universidade Estadual de Campinas
}

\section{RESUMO}

O enceramento diagnóstico consiste no planejamento da reabilitação oral, apresentando soluções customizadas para cada caso. O objetivo do presente trabalho é apresentar uma revisão crítica da literatura científica, apresentando conceitos, definições, empregos e limitações do enceramento diagnóstico. Entre os objetivos desta técnica está o de oferecer, por meio de estudo prévio, uma resolução clínica efetiva ao paciente. O desfecho clínico proporcionado por esta ferramenta é a devolução da anatomia oclusal e os determinantes da oclusão para que haja uma perfeita harmonia entre ela, os movimentos mandibulares e a cinética condilar. Esta técnica apresenta diferentes metodologias que buscam um objetivo final único: a devolução do equilíbrio do sistema estomatognático. Desta forma, o enceramento diagnóstico possibilita o planejamento personalizado para cada caso clínico, resultando em uma perfeita função e estética da prótese dental e consequente harmonia do sistema.

Palavras-chave: reabilitação bucal, oclusão dentária, sistema estomatognático.

\begin{abstract}
THE diagnostic wax-up consists in planning oral rehabilitation, presenting customized solutions for each case. The aim of this paper is to present a critical review of scientific literature, presenting concepts, definitions, uses, and limitations of diagnostic wax-up. One of the objectives of this technique is to provide, through previous study, an effective clinical solution to the patient. The clinical outcome provided by this tool is the recovering of the occlusal anatomy and the occlusion determinants so there is a perfect harmony with mandibular movements and kinetic condylar. This technique presents different methodologies seeking a single goal: to recover the stomatognathic system's balance. Thus, the diagnostic wax-up allows for customized design for each clinical case, resulting in the dental prosthesis's a perfect function and aesthetics and the consequent harmony of the system.
\end{abstract}

Keywords: MOUTH REHABILITATION, DENTAL OCCLUSION, STOMATOGNATHIC SYSTEM. 


\section{INTRODUÇÃO}

Um planejamento reabilitador estéticofuncional envolve a integração de diversas especialidades da odontologia. A evolução do conhecimento e diagnóstico, bem como o desenvolvimento das técnicas e materiais restauradores, gera novas perspectivas que devem ser sempre atualizadas e confrontadas. Dentro desta expectativa, é fundamental um planejamento adequado e o conhecimento de novas técnicas por parte dos cirurgiões-dentistas. ${ }^{1}$

Para que a reabilitação oral tenha um prognóstico favorável, é necessário, dentro deste planejamento prévio, a integração entre cirurgião-dentista e técnico de laboratório. ${ }^{2,3,4}$ A obtenção do resultado desejado ao final do tratamento necessita de um adequado planejamento inicial, bem como conhecimentos da anatomia dentária, conceitos e dos determinantes de oclusão que desempenham papel fundamental na reabilitação oral, auxiliando o cirurgião-dentista a promover saúde para seus pacientes. ${ }^{2}$

Entre as ferramentas disponíveis para o estudo de um caso clínico e um correto planejamento, o enceramento diagnóstico (ED) é um método atualmente empregado entre os cirurgiões-dentistas e considerado imprescindível para a finalidade de orientar a reabilitação oral do paciente, e que irá auxiliar o cirurgião-dentista no planejamento das próteses dentais, sejam elas fixas ou removíveis. $^{5}$

O ED tem a finalidade de reconstruir a porção desgastada dos dentes e substituir os dentes ausentes, de modo a determinar corretamente o plano oclusal, os contatos simultâneos nos dentes posteriores e guia anterior. ${ }^{3}$

A técnica do ED tem a função de guiar o cirurgião-dentista no correto diagnóstico associado ao planejamento adequado bem como orientar na demonstração do caso clínico para o paciente envolvido, elucidando o trabalho a ser executado para que este paciente tenha uma imagem das possibilidades de tratamento e reconstrução funcional e estética. Por meio do ED é possível ter uma previsibilidade da estabilidade oclusal e liberdade dos movimentos mandibulares que estão diretamente associadas com o equilíbrio do sistema estomatognático. ${ }^{6}$

Atualmente, esta técnica também tem sido empregada na implantodontia, ao fornecer os possíveis locais para a instalação dos implantes, bem como definir a localização, direção e inclinação, o alinhamento e relacionamento com os dentes remanescentes, facilitando, desta forma, a futura tarefa do técnico de laboratório na confecção, e do protesista, na instalação da prótese. $^{5}$

Assim, o presente artigo, que se fundamenta em uma revisão da literatura, objetiva enfatizar a utilização do enceramento diagnóstico e como o emprego desta técnica pode auxiliar no restabelecimento da oclusão dentária e contribuir com os aspectos funcionais do sistema estomatognático em casos de reabilitação oral.

\section{Materiais e Métodos}

O presente trabalho trata de uma revisão de literatura sobre enceramento diagnóstico. Para isso, realizou-se a coleta de trabalhos científicos em bancos de dados internacionais e nacionais: Pubmed, Scielo, Bbo, Medline e Lilacs. Utilizaram-se palavras-chave "wax-up", "diagnostic wax-up", "diagnostic wax", "oral rehabilitation" "prosthodontics" e "occlusal rehabilitation", podendo ser colocadas isoladas ou em conjunto. Foram selecionados artigos publicados no período de 1991-2012. 


\section{REVISÃo de LiteratuRA}

\section{ENCERAMENTO DIAGNÓSTICO - DEFINIÇÕES E CONCEITOS}

O enceramento diagnóstico pode ser definido como um procedimento em que restaurações e reabilitações são planejadas e desenvolvidas em cera para determinar e guiar os procedimentos clínicos e laboratoriais. ${ }^{4}$

O enceramento é feito a partir do modelo de gesso, no qual se reconstroem as porções desgastadas dos dentes e/ou dentes ausentes em cera para determinar os contatos dentários simultâneos e o plano oclusal desejados ao término da reabilitação oral. ${ }^{7,8}$

Desta forma, este método auxilia no diagnóstico e planejamento de casos de pacientes dentados, parcialmente dentados ou edentados e proporciona a individualização do tratamento. ${ }^{7,8}$

\section{ENCERAMENTO DIAGNÓSTICO - EMPREGO E USO}

O ED tem diversas indicações na reabilitação oral por meio de próteses dentárias fixas ou removíveis, unitárias ou extensas, ou sobre implante, e o emprego desta técnica é de fundamental importância para a previsibilidade funcional e estética que será obtida ao final da reabilitação protética. ${ }^{2}$

Para que 0 tratamento reabilitador seja satisfatório, os resultados devem ser previstos antes da confecção da restauração definitiva a fim de evitar decepções e repetições desnecessárias. ${ }^{4}$ Além disso, esta previsibilidade funcional e estética obtida com - ED também proporciona a comunicação entre a equipe odontológica e o paciente, pois permite a visualização final da reabilitação. É por meio da comunicação e ilustração tridimensional do caso clínico que o paciente adquire confiança e, posteriormente, satisfação com a reabilitação protética. ${ }^{3-5}$

Segundo Shirata et al. $^{7}$ e Pompeu e Prado, $^{8}$ o ED é uma etapa essencial na avaliação do paciente e é pela execução desse procedimento que se pode prever a posição final dos dentes, bem como o suporte de tecido duro e mole requerido, guiando o cirurgiãodentista quanto às modificações prévias no plano de tratamento.

Além disso, Simon e Magne ${ }^{4}$, Zani et al. ${ }^{2}$, Shirata et al. $^{7}$ e Pompeu e Prado, ${ }^{8}$ afirmam que o enceramento diagnóstico pode ser empregado na confecção do guia cirúrgico utilizado na instalação de implantes. Quando utilizado para essa finalidade, o planejamento pode ser realizado de forma integrada, podendo os implantodontistas e protesistas avaliar o caso antes da cirurgia e planejar, a partir do enceramento diagnóstico, o posicionamento de implantes osseointegrados e, consequentemente, das futuras próteses sobre implantes e, desta forma, garantir o resultado final ideal da prótese dentária.

Pompeu e Prado $^{8}$ relataram que a técnica de ED pode ser importante também para evitar o sobrecontorno de próteses fixas na região cervical e, desta forma, facilitar o acesso à higienização e, consequentemente, a diminuição do acúmulo de placa bacteriana, ${ }^{8,9,10}$ proporcionando longevidade ao tratamento reabilitador.

\section{A CONTRIBUIÇÃO DO ENCERAMENTO DIAGNÓSTICO NO SISTEMA ESTOMATOGNÁTICO \\ A fisiologia do sistema estomatognático} envolve as funções de mastigação, deglutição, respiração, fonação e função postural. A oclusão dentária está intimamente relacionada com esse sistema, bem como com os ossos, músculos, ligamentos e o sistema vascular e nervoso. ${ }^{11}$

Em uma reabilitação oral com o uso do ED, as disposições, a forma e a estética correta dos dentes são determinadas a partir dos princípios de oclusão e da harmonia entre os movimentos mandibulares. Estes princípios vão assegurar a prevenção das disfunções 
musculares e dos distúrbios da articulação temporomandibular, e resultam na estabilidade do sistema estomatognático. ${ }^{8}$

Visando à harmonia do sistema estomatognático para os pacientes que necessitam de reconstrução protética extensa, torna-se imprescindível a realização do enceramento diagnóstico. ${ }^{7,8}$

\section{ENCERAMENTO DIAGNÓSTICO}

\section{E A OCLUSÃO DENTÁRIA}

A oclusão dentária apresenta posições diversas em virtude das movimentações mandibulares. A oclusão pode ser cêntrica ou excêntrica, a qual pode ser desviada para direita ou para a esquerda, protruída ou retruída. Outro posicionamento a ser considerado é o de máxima intercuspidação habitual, em que a oclusão está relacionada ao máximo número de contatos dentários, independentemente da posição dos côndilos na cavidade articular. ${ }^{10}$

Ao término da reabilitação oral, para a obtenção de estabilidade oclusal, liberdade de movimentos mandibulares e ausência de interferências, devem ser mantidas a dimensão vertical, a guia anterior ou incisal de desoclusão e a relação cêntrica ou habitual. Estes aspectos são importantes para a manutenção do equilíbrio do sistema estomatognático ${ }^{2}$ a fim de garantir um prognóstico favorável. Para tanto, é preciso um planejamento amplo, previamente à confecção da prótese, para verificação da normalidade do sistema estomatognático e a necessidade de modificação dos determinantes da oclusão relacionados ao posicionamento mandibular, altura e forma de cúspides. ${ }^{11}$

Desta forma, a técnica de enceramento diagnóstico pode ser importante para promover estabilidade dentária a partir do restabelecimento dos aspectos oclusais, tais como as curvas de Spee e Wilson, as guias incisivas e caninas, os trespasses horizontal e vertical e a altura das cúspides e do plano oclusal, ${ }^{2}$ que, por sua vez, auxiliam na diminuição do tempo necessário para a realização de ajustes oclusais..$^{7,8}$

\section{TÉCNICAS DE ENCERAMENTO DIAGNÓSTICO}

Existem diversas técnicas de enceramento diagnóstico descritas naliteratura. Dentre elas, a técnica do enceramento progressivo e convencional é realizada a partir da obtenção das arcadas dentárias em modelos de gesso, posteriormente montados em articulador semiajustável (ASA). Sobre os modelos de gesso, com o auxílio de cera, os dentes são esculpidos nos espaços edêntulos, ou completam-se os dentes desgastados e/ou fraturados. ${ }^{8}$ A partir do enceramento determinase o posicionamento e a forma da prótese dentária definitiva que será posteriormente instalada. $^{2}$

Pompeu e Prado ${ }^{8}$ relataram a técnica de acréscimo em cera, considerada fácil e rápida, além de ser utilizada, tanto manualmente pelo gotejamento e escultura manual como pelo uso de moldes industrializados pré-fabricados que apresentam a mesma eficácia do enceramento diagnóstico convencional, mas sem a necessidade de esculpir a superfície oclusal. Depois de obtido os modelos de estudo e da montagem em articulador ASA, utiliza-se o kit industrializado Conformix® para a confecção dos dentes ausentes. Os dentes são construídos em cera com o emprego do gotejador, lecron, cubeta metálica e lamparina, lapidados e posicionados atendendo aos princípios de oclusão.

Tarantola e Becker ${ }^{12}$ utilizam a técnica de enceramento feito com resina composta fotopolimerizável como uma técnica mais precisa. Esta técnica consiste na escultura anatômica com resina composta substituindo a cera.

Simon e Magne ${ }^{4}$ demonstraram dois métodos de enceramento diagnóstico. O primeiro, freehand method, consiste no enceramento prévio da restauração e posterior 
construção da restauração em resina composta diretamente no paciente, sem utilizar métodos adesivos, para o paciente ter consciência da futura restauração. O outro método, conhecido como enceramento por mock-up, é realizado em resina composta fotopolimerizável sobre o modelo de gesso. Após a obtenção do enceramento é realizado um molde com matriz de silicone, a qual é preenchida com resina composta, previamente fotopolimerizada, antes de ser levada à boca do paciente como restauração definitiva.

Apesar das diferentes técnicas, cabe ao cirurgião-dentista e técnico em prótese dentária avaliarem qual a melhor técnica a ser utilizada em cada caso, pois todas oferecem as características estéticas e funcionais desejáveis ao término da reabilitação protética.

\section{Dıscussão}

O tratamento de pacientes com desgaste e/ou falta de dente, utilizando próteses fixas ou removíveis, exige o estudo e planejamento individualizado de cada caso. Após a montagem dos modelos em articulador semiajustável e realização do enceramento diagnóstico, são fornecidas as informações necessárias para avaliar as opções de tratamento do paciente. ${ }^{6}$

A montagem dos modelos de estudo em articulador oferecem duas vantagens principais no diagnóstico. Primeiro, melhora a visualização do relacionamento estático e dinâmico dos dentes e possibilita a observação da oclusão do paciente que pode ser visualizada por lingual, a qual não pode ser examinada clinicamente. A segunda vantagem diz respeito à facilidade de visualização dos contatos oclusais por meio dos movimentos mandibulares. No articulador, os movimentos mandibulares do paciente e os contatos oclusais podem ser observados sem a influência do sistema neuromuscular, o que tolera alteração na dimensão vertical de oclusão (DVO) para futura instalação da prótese. ${ }^{6}$ Dessa maneira, a utilização do articulador semiajustável tornase imprescindível na montagem dos modelos de estudo para diagnóstico do caso clínico.

Com os modelos montados em articulador semiajustável, as disposições, a forma e a estética dos dentes serão determinadas pelo enceramento diagnóstico. A partir do ED podese prever a estabilidade oclusal, a liberdade de movimentos mandibulares e a ausência de interferências, que, por sua vez, são essenciais para o equilíbrio do aparelho estomatognático. ${ }^{8}$ Desta forma o ED deve ser rotina na prática clínica odontológica para todos os pacientes que necessitem de reabilitação oral. ${ }^{13}$

Apesar de apresentar diversas indicações em reabilitação oral, há, na literatura, controvérsias a respeito da utilização do enceramento diagnóstico em relação ao custo/benefício. Segundo Bidra ${ }^{14}$, a duplicação do enceramento diagnóstico é um método rápido, eficaz e econômico para a confecção de próteses fixas sobre implante. No entanto, Dalvit et al., ${ }^{15}$ relataram que, apesar de o ED ser muito utilizado para o diagnóstico de pacientes que procuram tratamento protético, esta técnica não é rotina em consultório odontológico, pois demanda tempo e não resulta em benefícios imediatos.

Neste contexto, ressalta-se que o domínio da técnica de ED pelo cirurgiãodentista e do técnico em prótese dentária é de fundamental importância para a decisão de sua utilização, pois, quando corretamente indicada, pode auxiliar a comunicação entre o clínico e o paciente, além de contribuir com os cuidados de higienização, garantindo a satisfação por meio da previsibilidade funcional e estética do tratamento reabilitador. ${ }^{2}$

\section{Conclusão}

Com base na revisão de literatura, verifica-se que o enceramento diagnóstico apresenta soluções personalizadas para o 
caso a ser planejado, oferecendo, por meio de estudo prévio, uma resolução clínica efetiva ao paciente. Conclui-se ainda que o ED é de fundamental importância para as reabilitações bucais extensas, casos complexos, na comunicação com pacientes ansiosos pelo resultado e integração entre profissionais da área, resultando em uma perfeita função e estética da prótese dental e consequente harmonia do sistema estomatognático.

\section{ReferênCIAS Bibliográficas}

1. Viana PC, Correia A, Neves M, Kovacs Z, Neugbauer R. Soft tissue waxup and mock-up as key factors in a treatment plan: case presentation. Eur J Esthet Dent. 2012; 7(3): 310-23.

2. Zani IM, Rode SM, Santos JFF. O uso de resina composta como auxiliar na reabilitação oral. Rev Amb Odontol. 1991; 1(6): 119-22.

3. Kahng LS. Patient-dentist-technician communication within the dental team: using a colored treatment plan wax-up. J Esthet Restor Dent. 2006; 18(4): 185-93.

4. Simon H, Magne P. Clinically based diagnostic wax-up for optimal esthetics: the diagnostic mock-up. J Calif Dent Assoc. 2008; 36(5): 355-62.

5. Chiche CA, Pinault DC, Bassanta AD, Morgan G. Consideration for fabrication of implantsupported posterior restaurations. Int $\mathrm{J}$ Prosthodont. 1991; 4(1): 37-44.

6. Moslehifard E, Nikzad, S, Geraminpariah F, Mahboub F. Full-mouth rehabilitation of a patient with severely worn dentition and uneven occlusal plane: A clinical report. J Prosthodont. 2012; 21(1): 56-64.
7. Shirata OC, Bassanta $A D$, Silva AR. As influências dos determinantes da oclusão no enceramento de diagnóstico. Odonto. 1999; 7(16): 46-50.

8. Pompeu JGF, Prado VLG. Técnica fácil e rápida de enceramento diagnóstico utilizada no atendimento odontológico público na Universidade Federal do Piauí - UFPI. Int J Dent. 2004; 3(1): 308-11.

9. Sonoda HM, Bassanta AD, Silva AR. Enceramento dos casquetes para retentores com problemas periodontais. Rev ABO Nac. 1994; 2 (1): 33-5.

10. Bassanta AD. A importância do enceramento de diagnóstico na reabilitação oral. Rev Bras Odontol. 1992; 49(6): 10-14.

11. Saba S. Design of a cast bar reinforced provisional restoration for the management of the interim phase in implant dentistry. J Can Dent Assoc. 1999; 65(3): 160-162.

12. Tarantola GL, Becker IM. Definitive diagnostic waxing with light-cured composite resin. J Prosthet Dent. 1993; 70(4): 315-19.

13. Carvalho BCF. Utilização de imagem digital para diagnóstico e planejamento estético. Rev Dent Press Estética. 2006; 3(1): 72-82.

14. Bidra AS. Chair-side fabrication of a fixed implant-supported prosthesis in an edentulous mandible from a diagnostic wax-up: a clinical report. J Oral Implantol. 2012; 38(3): 291-97.

15. Dalvit DL, Parker MH, Cameron SM. Quick chairside diagnostic wax-up. J Prosthet Dent. 2002; 87(5): 581-2.

Submetido em: 13-4-2013

Aceito em: 4-6-2013 